Relations industrielles

Industrial Relations

\title{
Keeping Pace with Automation. Special Report No. 7. American Management Association. New York, 1956. 136 pp.
}

\section{Roger Chartier}

Volume 11, numéro 3, juin 1956

URI : https://id.erudit.org/iderudit/1022637ar

DOI : https://doi.org/10.7202/1022637ar

Aller au sommaire du numéro

Éditeur(s)

Département des relations industrielles de l’Université Laval

ISSN

0034-379X (imprimé)

1703-8138 (numérique)

Découvrir la revue

Citer ce compte rendu

Chartier, R. (1956). Compte rendu de [Keeping Pace with Automation. Special Report No. 7. American Management Association. New York, 1956. 136 pp.] Relations industrielles / Industrial Relations, 11(3), 222-222.

https://doi.org/10.7202/1022637ar

Tous droits réservés (C Département des relations industrielles de l’Université Laval, 1956
Ce document est protégé par la loi sur le droit d'auteur. L’utilisation des services d'Érudit (y compris la reproduction) est assujettie à sa politique d'utilisation que vous pouvez consulter en ligne.

https://apropos.erudit.org/fr/usagers/politique-dutilisation/ 
dimensions presque... bibliques qui se targue d'expliquer «tous les procédés importants du domaine des opérations industrielles »! Trop de matière nous impose toujours des doutes sur la qualité. L'effort, on le conçoit, est fort louable: à l'ingénieur comme à l'administrateur qui demain oeuvreront dans la grande entreprise industrielle, on entend fournir des vues sur un peu tout, dans les limites d'un même volume. II en résulte une inévitable dispersion dans la matière, des études nombreuses aux mérites fort variables, des chevauchements presque fatals autour de l'organisation scientifique du travail (scientific management), fil conducteur d'" approches » souvent fort disparates, d'études qui, quoique assez longues, n'en restent pas moins presque toujours superficielles. Bref, un volume de ce genre constitue toujours un compromis: on n'y règle jamais rien bien à fond, mais on y parle un peu de tout. Et la multiplicité des auteurs rend difficile cette unité, cet ordre de la pensée et du style qu'on espère trouver entre les deux couvertures d'un même livre.

Les remarques qui précèdent ne doivent pas faire oublier les mérites réels, et fort nombreux, des dix-huit collaborateurs de ce volume peu commun. L'article de Ernest Dale sur la structure de l'entreprise n'apporte que peu de nouvelles lumières à l'administrateur de métier, mais il se présente bien et agence sa matière avec art. Les «Managerial Economics » de Joel Dean, concises et à point, méritent lecture et re-lecture; cet article, qui s'adresse à l'administrateur aux prises avec des problèmes économiques, a comme pendant, pour l'ingénieur, l'article suivant de Paul T. Norton. Le texte de Dale Yoder sur la Direction du Personnel est probablement ie plus faible de cette collection. Marvin E. Mundel reprend, dans un texte de plus de cent pages, l'essentiel de la seconde édition de son Motion and Time Study (Prentice-Hall, 1955). Suivent des articles techniques sur la climatologie industrielle, l'hygiène industrielle et la sécurité au travail. Puis des textes compétents sur les «Factory Systems and Procedures », le «Factory Planning and Materials Handling », l'«Industrial Standardization » et le «Tool Engineering ».

Deux articles de Bowker et Lieberman «Industrial Statistics 》 et Lewis 《Inspection and Quality Control» s'atta- chent à la description de la méthode statistique en tant qu'appliquée aux problèmes de production et de contrôle dans l'industrie moderne. Un article de A. W. Swan porte plus précisément sur la recherche dans l'industrie. Le texte de Raymond Villers porte sur la comptabilité industrielle. Enfin, je souligne le demier article de la série, celui de William Gomberg, qui porte sur les attitudes syndicales à l'endroit du génie industriel, dit «scientific management 》. En soixante-deux pages d'un texte serré, Gomberg, après Hoxie, Perlman, Tannenbaum, McKelvey, Philip Murray ( \& Cooke), Barkin, et bien d'autres, tente d'expliquer, historiquement et philosophiquement, l'attitude globale des travailleurs en face de la technique de production à la Taylor, Gilbreth, et al. Il analyse et critique l'analyse de l'évaluation des tâches, l'analyse des temps et des mouvements, la question des stimulants à la production, les tendances de la psychologie industrielle, etc.

Ce volume, fruit d'un effort collectif, pourra, malgré les vices inhérents à la formule elle-même, rendre de très grands services à un lecteur patient et qui ne se laisse pas rebuter facilement par la masse et par la dispersion.

Keeping Pace with Automation. Special Report No. 7. American Management Association. New York, 1956. 136 pp.

Ce petit volume sur l'automation ramasse sous un format commode les conférences prononcées lors d'une rencontre de la Manufacturing Division de l'AMA à New-York. en 1955.

On y étudie surtout l'automation comme un fait technologique. Albert Sperry cffre des considérations intéressantes sur la nature du phénomène, alors que John Diebolld parle de ses applications. D'autres conférenciers parlent tour à tour des techniques et des méthodes de l'automation, des machines-outils et des contrôles automatiques.

La deuxième partie du volume contient quatre cas typiques d'industries - télévision, carborundum, produits du carton et papier, produits alimentaires où l'automation a connu des applications très importantes.

Une troisième partie ouvre des horizons et s'essaie à des prédictions. Rien sur les conséquences économico-sociales de l'automation. 